\title{
Cystic Tumor of the Atrioventricular Node
}

National Cancer Institute

\section{Source}

National Cancer Institute. Cystic Tumor of the Atrioventricular Node. NCI Thesaurus.

Code C45754.

A multicystic tumor arising in the inferior interatrial septum in the region of the atrioventricular node. The vast majority of patients present with complete heart block and a minority with partial heart block. Sudden death is reported in approximately $10 \%$ of the cases. It is a morphologically benign tumor composed of cuboidal, transitional, or squamoid cells. The cells may also show sebaceous differentiation and originate from the endoderm. 